Прохорова Марина Леонидовна

доктор юридических наук, профессор, профессор кафедры уголовного права и криминологии Кубанского

государственного университета

Марков Арман Агасиевич

магистрант кафедры уголовного права и криминологии Кубанского

государственного университета

\section{ВЗЯТОЧНИЧЕСТВО: НЕКОТОРЫЕ ПРОБЛЕМНЫЕ ВОПРОСЫ РЕГЛАМЕНТАЦИИ УГОЛОВНОЙ ОТВЕТСТВЕННОСТИ И КВАЛИФИКАЦИИ}

Аннотация:

В статье рассмотрен ряд проблемных вопросов квалификации преступлений, связанных со взяточничеством. В частности, представлены спорные ситуации квалификации получения взятки при наличии квалифицирующего признака сопряженности ее с вымогательством предмета преступления. Еще раз обращается внимание на суть понятия «вымогательство взятки», поднимается вопрос соотношения ролей вымогателя взятки должностного лица и посредника во взяточничестве, фактически выполняющего функции вымогателя; предлагается самостоятельная криминализация вымогательства взятки с учетом исторического законодательного опыта. Обращаясь лишь начавшей формироваться судебной практике, учитывая намеченные векторы развития отечественного гражданского законодательства, авторы поднимают вопрос о включении в понятие "взятка" качественно новых объектов граждан ского оборота, в частности криптовалюты.

Ключевые слова

посредничество во взяточничестве, взятка, посредник, взяткодатель, взяткополучатель, обещание посредничества во взяточничестве, вымогательство взятки, криптовалюта.
Prokhorova Marina Leonidovna

LL.D, Professor, Criminal Law and Criminal Studies Department, Kuban State University

Markov Arman Agasievich

Master's Degree student, Criminal Law and Criminal Studies Department Kuban State University

BRIBERY: PROBLEMATIC REGULATION OF CRIMINAL LIABILITY AND QUALIFICATION

\begin{abstract}
Summary:
The study discusses the problematic issues of qualifying bribery crimes. In particular, the paper deals with contentious qualification of bribing if there is a qualifying sign of its conjugation with the extortion of the subject matter of a crime. The emphasis is placed on the essence of the concept of extortion. The study addresses the issue of the relationship between an extortioner (an official) and a mediator in bribery, which indeed serves as an extortioner. It is proposed to criminalize extortion independently, considering the legislative practices. Referring to the emerging civil case law in Russia in this regard, the authors discuss the possibility of expanding the list of elements regarded as a subject matter of bribery and including cryptocurrency, a qualitatively new civil turnover element, in the concept of bribe.
\end{abstract}

Keywords: bribery mediation, bribe, mediator, briber, bribe-taker, promise of bribery mediation, extortion, cryptocurrency.

Прежде чем переходить к непосредственному рассмотрению дискуссионных вопросов квалификации вымогательства взятки, следует упомянуть, что это деяние, ранее существовавшее в качестве самостоятельного преступного посягательства, впервые было отнесено к квалифицирующему получение взятки признаку в Декрете 1918 г. «О взяточничестве» наряду с особыми полномочиями служащего, а также с нарушением служащим своих обязанностей. В дальнейшем «статус» вымогательства взятки в качестве квалифицированного состава ее получения был воспринят как Уголовными кодексами РСФСР 1922, 1926 и 1960 гг., так и действующим Уголовным кодексом РФ (п. «б» ч. 5 ст. 290).

Начиная с 30-х гг. XX в. А.А. Ганиным, А.Н. Трайниным и некоторыми другими авторами рассматривался вопрос о природе вымогательства взятки и его отграничении от вымогательства как от преступления против собственности. Так, А. Старш под вымогательством взятки предлагал понимать не просто «создание обстоятельств, понуждающих дать взятку», а собственно вымогательство, созвучное деянию, предусмотренному расположенной в гл. VII («Имущественные преступления») ст. 174 УК РСФСР 1926 г. (вымогательство), «т. е. требование взятки под страхом насилия какого-либо, оглашения позорящих сведений или обстоятельств, истребления имуще- 
ства какого-либо и т. п.» [1, с. 62-68]. Таким образом, названным автором содержание соответствующего воздействия должностного лица отождествлялось с угрозами, свойственными общеуголовному преступлению.

Официальное толкование понятия «вымогательство взятки», хотя оно и появилось еще в Уголовном кодексе 1922 г., впервые было предложено в постановлении Пленума Верховного Суда СССР № 9 от 31 июля 1962 г. «О судебной практике по делам о взяточничестве». Согласно соответствующему разъяснению, таковым признавалось «требование должностным лицом взятки под угрозой совершения таких действий по службе, которые могут причинить ущерб законным интересам взяткодателя, либо умышленное поставление последнего в такие условия, при которых он вынужден дать взятку для предотвращения вредных последствий его правоохраняемым интересам» (абз. «г» п. 8) [2, с. 472]. Практически тождественная формулировка воспроизводилась в постановлениях Пленума Верховного Суда СССР № 6 от 23 сентября 1977 г. и № 3 от 30 марта 1990 г. «О судебной практике по делам о взяточничестве». Совершенно очевидно, что толкующий орган связал вынуждающее воздействие на потенциального взяткодателя с угрозами, сопряженными с использованием соответствующих служебных функций должностного лица.

В ныне действующем постановлении Пленума Верховного Суда РФ от 9 июля 2013 г. № 24 «О судебной практике по делам о взяточничестве и об иных коррупционных преступлениях» (далее - постановление № 24) представлено созвучное понимание содержания вымогательства взятки (п. «б» ч. 5 ст. 290 УК РФ). Это как требование должностного лица дать взятку, сопряженное с угрозой совершить действия (бездействие), могущие причинить вред законным интересам лица, так и заведомое создание условий, при которых лицо вынуждено передать взятку для предотвращения негативных последствий для своих правоохраняемых интересов [3]. При этом анализ соответствующих положений названного постановления позволяет заключить, что истоком обещаемого вреда выступает именно служебная деятельность должностного лица.

Вместе с тем, несмотря на наличие официального толкования вымогательства взятки и сорормированность доктринального представления о содержании этого понятия, не все его аспекты понятны и очевидны. В первую очередь вопросы вызывает противопоставление вымогательства взятки правоохраняемым интересам. Согласно п. 18 постановления № 24, должностное лицо может вымогать взятку лишь за совершение законных действий, так как с их помощью реализуется правоохраняемый интерес, достижение которого посредством совершения незаконных действий невозможно априори. Действительно, сложно представить ситуации, при которых потенциальному взяткодателю угрожали бы совершением законных действий, способных причинить вред его правоохраняемым интересам.

Однако однобокость данной позиции Пленума Верховного Суда РФ ярко прослеживается при рассмотрении следующей ситуации. Предположим, А. совершил преступление, и следователь Б., угрожая ему привлечением к уголовной ответственности, суровым наказанием и т. д., предлагает «решить вопрос» за определенную сумму. На первый взгляд, явно присутствует вымогательство, но наличествует ли оно в уголовно-правовом плане? В соответствии с постановлением № 24 действия следователя Б. хоть и схожи фрактически с вымогательством, не будут считаться таковым вследствие того, что лицо «вымогает» взятку за уклонение от уголовной ответственности, то есть за совершение незаконных действий. Данные деяния получают уголовноправовую оценку как «простое» получение взятки (естественно, при отсутствии иных квалифицирующих признаков).

Наряду с этим, формула простой взятки: взяткодатель $\rightarrow$ взяткополучатель неприменима, так как в данном случае она видоизменена: воздействие взяткополучателя $\rightarrow$ взяткодатель $\rightarrow$ взяткополучатель. Мы видим, что «блок» действий взяткополучателя, предшествующий фоормированию умысла у взяткодателя, ускользает из поля зрения правоприменителя из-за формального разграничения действий взяткополучателя на законные и незаконные.

В то же время стоит отметить, что кажущиеся на первый взгляд незаконными действия могут оказаться вполне правомерными при их более тщательном анализе. Обратимся к приведенному ранее примеру и придадим ему конкретику. То же лицо А. совершило преступление, предусмотренное ч. 1 ст. 105 УК РФ, но было введено в заблуждение следователем Б., который убедил А., что им исполнено посягательство, предусмотренное ч. 2 ст. 105 УК РФ, соответственно угрожая более строгим наказанием, условиями отбывания лишения свободы и т. д. И с целью улучшения положения А. следователь Б. «просит» определенную сумму денег для переквалификации деяния на ч. 1 ст. 105 УК РФ.

С точки зрения А., действия следователя по переквалификации преступления носят незаконный характер, так как он, будучи введенным в заблуждение, полагает, что следователь Б. «уводит» его от уголовной ответственности за более тяжкое посягательство. Но фактически следователь получает взятку за правильную уголовно-правовую оценку содеянного. Тем самым он 
задействует установленный законом механизм привлечения к уголовной ответственности, направленный на защиту прав всех участников судопроизводства, в том числе и прав А.

Встает закономерный вопрос: субъективное отношение кого из указанных лиц будет играть определяющую роль при квалификации: введенного в заблуждение А., считающего действия следователя Б. по переквалификации незаконными, или следователя Б., осознающего законность действий, за совершение которых он вымогает взятку?

На наш взгляд, приведенная ситуация показывает, что разграничение вымогательства взятки на основе критерия законности совершаемых за нее действий приводит порой к неадекватной квалификации соответствующих деяний. Тем не менее выделение вымогательства взятки за совершение законных действий как более тяжкого преступления безусловно обоснованно, поэтому полагаем, что наиболее оптимальным выходом является изложение п. 18 постановления № 24 в новой редакции, согласно которой критерий «законности» действий будет носить объективный характер. Учитывая законодательную регламентацию роли подстрекателя, приведенный круг действий в ч. 4 ст. 33 УК РФ, совершаемых им, позволяет квалифицировать фактическое вымогательство взятки за совершение незаконных действий должностным лицом как подстрекательство (ч. 4 ст. 33 УК РФ) к даче взятки по соответствующей части ст. 291 УК РФ. Важно заметить, что подобная квалификация возможна как при прямом требовании передачи взятки (уговоры, угрозы), так и при заведомом создании условий, при которых лицо вынуждено передать взятку (склонение иным способом). В противном случае неправомерное воздействие взяткополучателя на фрормирование умысла взяткодателя не получит должной уголовно-правовой оценки правоприменителем. Таким образом, взяткополучатель будет нести ответственность по совокупности преступлений.

Внимания требует и случай перекладывания функции вымогателя взятки с должностного лица на посредника. В соответствии с абз. 1 п. 18 постановления № 24, вымогателем взятки может признаваться лишь должностное лицо. Но в п. 19 указано, что, если вымогательство с согласия или по указанию должностного лица осуществлялось другим лицом, не являющимся получателем взятки, действия последнего при наличии оснований должны оцениваться как посредничество во взяточничестве по соответствующим частям ст. 291.1 УК РФ. Обращение к ст. 291.1 УК РФ позволяет вести речь о двух фрормах посредничества:

1) непосредственная передача взятки по поручению взяткодателя или взяткополучателя;

2) иное способствование взяткополучателю и (или) взяткодателю в достижении либо реализации соглашения между ними о получении и даче взятки в значительном размере.

Таким образом, возможность выбора невелика, и очевидно, что вымогательство взятки соотносимо с иным способствованием взяткополучателю и (или) взяткодателю в достижении либо реализации соглашения между ними.

Как уже отмечалось, угрозы или деяния, ставящие взяткодателя в безвыходное положение, образуют вымогательство взятки. С.И. Ожегов трактует соглашение как взаимное согласие (единомыслие, общность точек зрения), договоренность [4, с. 741]. Следовательно, возникает закономерный вопрос: отождествляет ли законодатель взаимное согласие лиц и вынужденные действия одного, совершенные под воздействием угроз другого? Налицо уже не просто расширительное толкование нормы уголовного права, а криминализация деяний посредством включения их в рамки состава уже существующего, но не соответствующего по природе и содержанию преступления. Доктриной уже поднимался данный вопрос, и наиболее верным решением в указанной ситуации, на наш взгляд, является квалификация действий вымогателя - недолжностного лица - как пособничества по ч. 5 ст. 33 и п. «б» ч. 5 ст. 290 УК РФ, поскольку ст. 291.1 УК РФ не предусматривает уголовную ответственность за посредничество в вымогательстве [5, с. 45-49].

Но если допустить, что вымогательство взятки, совершенное недолжностным лицом, образует состав посредничества во взяточничестве, то вполне логичной представляется квалификация действий лица, обещавшего или предложившего стать вымогателем в будущем, по ч. 5 ст. 291.1 УК РФ. В доктрине не раз высказывались мысли о необоснованности криминализации деяния, предусмотренного ч. 5 ст. 291.1 УК РФ [6, с. 65-67], являющей собой установление ответственности за «голый» умысел, что противоречит основополагающим началам уголовного права.

Учитывая все сложности, возникающие при применении норм, регламентирующих вымогательство взятки как признака, квалифицирующего ее получение, представляется возможным присоединиться к ранее высказанному в науке мнению о целесообразности обособления данного деяния в самостоятельный состав преступления [7, с. 132]. Тем более что подобная практика уже имела место в развитии российского права [8, с. 116]. В специальной литературе предлагается дополнить Уголовный кодекс РФ статьей 290.1 «Вымогательство взятки» [9, с. 132], исключив при этом соответствующий квалифицирующий признак из ст. 290 УК РФ. Нами она видится в следующей редакции: 
«1. Вымогательство взятки, то есть требование должностного лица, иностранного должностного лица, должностного лица публичной международной организации о передаче ему взятки, сопряженное с угрозой совершить входящие в его должностные полномочия действия (бездействие), которые могут причинить вред правам и законным интересам лица, а также заведомое создание условий, при которых лицо вынуждено передать взятку с целью предотвращения вредных последствий для своих прав и охраняемых законом интересов, - наказывается <...>.

2. Вымогательство взятки, совершенное группой лиц по предварительному сговору, а равно в значительном размере, - наказывается <...>.

3. Вымогательство взятки, совершенное организованной группой, а равно в крупном размере, - наказывается <...>.

4. Вымогательство взятки в особо крупном размере - наказывается <...>».

Предмет взятки четко определен в ч. 1 ст. 290 УК РФ. В качестве взятки могут выступать деньги, ценные бумаги, иное имущество, незаконное оказание услуг имущественного характера, а также предоставление иных имущественных прав. В доктрине давно ведутся оживленные споры относительно признания тех или иных объектов компонентами предмета взятки.

В первую очередь, речь идет об услугах неимущественного характера. Невключение законодателем данного объекта в состав предмета взяточничества вызвано рядом объективных причин. Так, гражданско-правовой наукой и законодательством не выработано однозначного и четкого разграничения услуг имущественного и неимущественного характера. Далее, конструктивным признаком преступлений, предусмотренных ст. 290, 291 УК РФ, выступает взятка в денежном выражении, а квалифицирующими обстоятельствами - она же в определенном размере, исчисляемом в денежном эквиваленте. Соответственно, оценка услуг неимущественного характера вызывает большие трудности в силу самой природы совершаемых действий. Кроме того, многие авторы подчеркивают корыстный характер преступления, говоря о том, что в случае оказания услуги неимущественного характера деяние перестает быть корыстным, следовательно, не может квалифицироваться по ст. 290 УК РФ [10, с. 196].

В то же время, апеллируя к корыстному характеру преступления, ученые выдвигали предложения о криминализации ситуаций, когда взяткодатель за деньги обращается к третьему лицу, которое и будет оказывать услуги неимущественного характера взяткополучателю. Такая модель совершения преступления рассмотрена Г.П. Новоселовым, который, рассуждая о возможности признания сексуальных услуг в качестве взятки, пишет, что фрактическое существование проституции в стране является признанным фактом. В свою очередь суть этого явления образует предоставление платных сексуальных услуг. Таким образом, если должностное лицо принимает сексуальные услуги, кем-либо оплаченные, осознавая данное обстоятельство, то налицо получение взятки, квалифицируемое по ст. 290 УК РФ. Аналогично, по мнению автора, должна оцениваться ситуация, когда постоянно занимающееся проституцией лицо безвозмездно вступает в половой контакт с должностным лицом с соответствующими намерениями [11, с. 609].

Как видим, подобная услуга неимущественного характера, если признать ее таковой, приобретает денежный эквивалент, в связи с чем, на наш взгляд, правильная квалификация деяния будет зависеть лишь от способности органов предварительного следствия верно установить точную сумму денег, переданных за оказание услуги.

Что касается оценки сексуальных услуг в качестве предмета взятки, то мнения ученых по этому вопросу расходятся. Как отмечено ранее, Г.П. Новоселов предлагает признавать их в качестве взятки, аргументируя свою позицию тем, что фактически такие услуги существуют, оказываются и имеют свою цену. Б.В. Волженкин обращает внимание на лицо, оказывающее данные услуги. Согласно его точке зрения, взяточничество отсутствует, если в сексуальные отношения с должностным лицом вступает сам «взяткодатель», заинтересованный в совершении им определенных действий, «поскольку подобные услуги не являются имущественными» [12, с. 197].

В специальной литературе высказываются мнения о возможности признания информации компонентом предмета взятки. Так, М.В. Феоктистов, рассуждая по этому вопросу, отмечает, что информация как таковая не обладает экономической, потребительской стоимостью. Вместе тем, по мнению автора, она может быть признана предметом взятки в следующих ситуациях: взяткодатель собирает сведения самостоятельно; оплачивает работу других лиц по сбору, анализу, систематизации информации; поручает соответствующие не входящие в круг их служебных полномочий действия с информацией своим подчиненным, выполняющим их безвозмездно [13, с. 216-217].

Оценивая данную позицию, А.В. Грошев верно подмечает, что в приведенной ситуации речь скорее идет об оказании информационных услуг как о предмете взятки, а не о самой информации. Указывая на необходимость денежной оценки, автор делает вывод, что в случае отсутствия оплаты соответствующих услуг отсутствует и сама вятка [14, с. 37]. 
С развитием новых технологий перед законодателем встает вопрос о необходимости эффективного регламентирования качественно новых общественных отношений. Последние несколько лет учеными-правоведами предпринимались попытки включения в сложившуюся систему объектов гражданского права криптовалюты, что вызвано ее постепенным распространением и проникновением из виртуального мира в мир реальный.

Высказывались различные точки зрения относительно природы криптовалюты, но единый подход до сих пор отсутствует.

С точки зрения уголовного права, можно выделить две фрормы «присутствия» криптовалюты в преступных посягательствах:

- криптовалюта как средство совершения преступления;

- криптовалюта как предмет преступного посягательства.

Первый вариант не вызывает у судов проблем при квалификации преступлений, в частности, например, связанных с незаконным оборотом наркотических средств. Невзирая на неочевидный денежный эквивалент, наличие транзакций криптовалют подтверждает фракт оборота наркотических средств, так как их стоимость в большинстве случаев, да и способ приобретения в целом не играют роли в процессе квалификации, в связи с чем использование криптовалюты не требует глубокой правовой оценки. В качестве иллюстрации можно привести выдержки из соответствующих судебных решений: «...13.12.2018 г. ... Д. посредством сети “Интернет“ произвел электронный перевод денежных средств в неустановленной сумме в децентрализованную цифровую криптовалюту “биткоин“, которой произвел оплату приобретаемого наркотического средства в крупном размере...» [15]; «...Реализуя свои преступные намерения, 3. 11.12.2018 г. через сеть "Интернет“ заказал у не установленного следствием лица наркотическое средство гашиш... переведя на указанный сайт электронные деньги (криптовалюта) в размере 40 тыс. руб. со своего счета. После этого неустановленное лицо сообщило 3. о местонахождении тайника, в котором находилось заранее приготовленное наркотическое средство гашиш в крупном размере» [16]; «X., используя свой сотовый телефон, с банковской карты перевел 8000 руб. на банковскую карту "Tinkoff MasterCard“, с которой в последующем обменял указанную сумму денег на криптовалюту “биткойны“ и перевел их на неустановленный счет на сайте, тем самым оплатив заказанные им наркотические средства и психотропные вещества» [17].

Что же касается второй из ранее указанных форм, то, на наш взгляд, криптовалюта может выступать в качестве предмета взятки по ряду причин, несмотря на полное отсутствие какоголибо законодательного регулирования.

В отличие от упомянутых выше услуг неимущественного характера, денежная оценка переданной криптовалюты не вызывает трудностей, так как по своему назначению она - новый вид валюты. Каждая валюта обладает свойством конвертирования, а наличие «официального» курса для каждого вида криптовалюты значительно упрощает данный процесс.

Учитывая, что криптовалюта в настоящее время не имеет правового статуса с точки зрения цивилистики, она исключена из гражданского оборота. Однако судебная практика в большинстве случае признает предметы, ограниченные в обороте или вовсе из него изъятые, в качестве предмета взятки, так как их имущественный характер не вызывает сомнений. Таким образом, имущественный характер криптовалюты также бесспорен.

Вместе с тем, пока законодателем вырабатывается модель правовой регламентации [18], суды уже не раз сталкивались с криптовалютой. Судебная практика при этом складывается весьма противоречиво. Так, решением Ряжского районного суда Рязанской области № 2-160/20172160/2017 М-129/2017 М-129/2017 от 26.04.2017 по делу № 2-160/2017 установлено, что, согласно информации Центрального банка РФ от 27.01.2014 «Об использовании при совершении сделок «виртуальных валют», в частности, Биткойн» [19], по «виртуальным валютам» отсутствует обеспечение и юридически обязанные по ним субъекты. Операции по ним носят спекулятивный характер, осуществляются на так называемых «виртуальных биржах» и несут высокий риск потери стоимости. Биткойн не подпадает под определение электронных денежных средств, содержащееся в п. 18 ст. 3 Федерального закона от 27.06.2011 № 161-Ф3 «О национальной платежной системе», а также под понятие платежной системы, сформулированное в п. 20 ст. 3 этого же Закона. Биткойн также не является иностранной валютой (п. 2 ч. 1 ст. 1 Федерального закона от 10.12.2003 № 173-Ф3 «О валютном регулировании и валютном контроле») и не подпадает под объекты гражданских прав, перечисленные в ст. 128 ГК РФ, не являясь вещью (товаром), наличными или безналичными деньгами, бездокументарными ценными бумагами и имущественными правами. Учитывая изложенное, суд заключил, что любые операции с криптовалютой лежат вне поля правового регулирования, следовательно, не могут повлечь каких-либо правовых последствий [20].

В то же время постановлением Первомайского районного суда г. Ижевска № 1-11/2019 1439/2018 от 30.01.2019 по делу № 1-11/2019 установлено, что Д. использовался обезличенный 
электронный счет (биткоин-кошелек), на который в качестве оплаты приобретения наркотических средств поступали денежные средства - российские рубли, заранее конвертированные потребителями этих препаратов в единицы криптовалюты (биткоины), которые обвиняемый в дальнейшем конвертировал в российские рубли и переводил на различные банковские карты. Его действия были квалифицированы по ч. 1 ст. 174.1 УК РФ [21]. Таким образом, в данном случае (как и в приведенных в тексте несколько ранее) криптовалюта была приравнена судом к денежным средствам или иному имуществу путем привязки к денежному эквиваленту криптовалюты, так как при сбыте наркотиков Д. получал не деньги, а именно криптовалюту. Легализация производилась посредством ее конвертации в рубли.

Итак, несмотря на неоднозначный подход судов, с распространением «финансовых» операций с использованием криптовалют практика их деятельности начала трансформироваться, в результате чего постановлением Девятого арбитражного апелляционного суда от 15 мая 2018 г. № 09АП-16416/2018 [22] установлено, что в силу диспозитивности норм гражданского права в ГК РФ отсутствует закрытый перечень объектов гражданских прав. Поскольку действующее гражданское законодательство не содержит всеобъемлющего понятия «иное имущество», упомянутое в ст. 128 ГК РФ, с учетом современных экономических реалий и уровня развития информационных технологий допустимо максимально широкое его толкование.

Доводы суда о недопустимости применения к криптовалютам по аналогии норм, регулирующих сходные отношения, противоречат положениям ст. 6 ГК РФ, согласно которым при отсутствии возможности использования аналогии закона права и обязанности сторон определяются исходя из общих начал и смысла гражданского законодательства (аналогия права) и требований добросовестности, разумности и справедливости.

По мнению суда апелляционной инстанции, криптовалюта, исходя из положений ст. 128 ГК РФ, не может быть расценена иначе как иное имущество.

Таким образом, можно констатировать, что включение криптовалюты в гражданский оборот - лишь вопрос времени, однако даже сейчас правоприменитель обладает необходимой правовой базой для ее признания в качестве предмета взятки.

Коррупция - опасное и крайне вредоносное социальное явление, присущее практически всем государствам [23], борьба с которым должна вестись систематически и беспрерывно. Тем не менее опрометчивое и порой не вполне взвешенное конструирование норм уголовного закона и их последующее толкование не только не способствует противодействию этому френомену, но и создает весомые предпосылки для его процветания, существенно затрудняя правоприменительный процесс.

Итак, для совершенствования норм УК РФ, регламентирующих ответственность за взяточничество, и практики их применения необходимо, на наш взгляд, дополнить УК РФ ст. 290.1 («Вымогательство взятки»); изложить п. 18 постановления № 24 в обновленной редакции, а также рассмотреть вопрос о возможности расширения перечня объектов, признаваемых предметом взятки.

\section{Ссылки и примечания:}

1. ЦИт. по: Будатаров С.М. Вымогательство взятки: уголовно-правовая характеристика // Сибирский юридический вестник. 2004. № 2. С. 62-68.

2. Сборник постановлений Пленума Верховного Суда СССР (1924-1970 гг.). М., 1970. С. 472.

3. О судебной практике по делам о взяточничестве и об иных коррупционных преступлениях : постановление Пленума Верховного Суда Российской Федерации от 9 июля 2013 г. № 24 (ред. от 03.12.2013 г.) [Электронный ресурс]. Доступ из СПС «КонсультантПлюс».

4. Ожегов С.И. Словарь русского языка : 70000 слов / под ред. Н.Ю. Шведовой. М., 1990. С. 741.

5. Бакрадзе А.А., Аминов Д.И. К вопросу о «сильных» и «слабых» сторонах постановления Пленума Верховного Суда РФ от 9 июля 2013 г. № 24 «О судебной практике по делам о взяточничестве и об иных коррупционных преступлениях» // Вестник Академии экономической безопасности МВД России. 2014. № 2. С. 45-49.

6. См., напр.: Прохорова М.Л., Марков А.А. Посредничество во взяточничестве: некоторые законотворческие и правоприменительные проблемы // Общество: политика, экономика, право. 2017. № 6. С. 65-67.

7. См.: Кузьмина Н.В. Законодательные механизмы в области противодействия коррупции: проблемы разработки и реализации // Вестник Костромского государственного технологического университета. Государство и право: вопросы теории и практики. 2015. № 1. С. 132.

8. Уложение о наказаниях уголовных и исправительных. СПб., 1845. С. 116.

9. Кузьмина Н.В. Указ. соч. С. 132.

10. Волженкин Б.В. Служебные преступления: комментарий законодательства и судебной практики. СПб., 2005. С. 196.

11. Уголовное право. Особенная часть / отв. ред. И.Я. Козаченко, З.А. Незнамова, Г.П. Новоселов. М., 1997. С. 609.

12. Волженкин Б.В. Указ. соч. С. 197.

13. Феоктистов М.В. Теоретические и практические проблемы взяточничества и коммерческого подкупа // Современные проблемы борьбы с транснациональной преступностью. Краснодар, 2000. С. 216-217.

14. Грошев А.В. Ответственность за взяточничество (вопросы теории и практики). Краснодар, 2008. С. 37.

15. См.: Приговор Верхнепышминского городского суда Свердловской области от 26 февраля 2019 г. по делу № 159/2019 [Электронный ресурc]. URL: https://sudact.ru/regular/doc/GKxY6mVm7g6l/ (дата обращения: 20.08.2019). 
16. См.: Приговор Завьяловского районного суда Удмуртской Республики от 21 февраля 2019 г. по делу № 1-63/2019 [Электронный ресурc]. URL: http://sudact.ru/regular/doc/7BTOpvqfUtdT/ (дата обращения: 20.08.2019).

17. См.: Приговор Вологодского городского суда Вологодской области от 11 февраля 2019 года по делу № 1-212/2019 [Электронный ресурc]. URL: http://sudact.ru/regular/doc/khphgkukNPVX/ (дата обращения: 20.08.2019).

18. В проекте Федерального закона «О цифровых финансовых активах и о внесении изменений в отдельные законодательные акты Российской Федерации» цифровой финансовый актив определяется как имущество в электронной форме, созданное с использованием шифровальных (криптографических) средств. Право собственности на данное имущество удостоверяется путем внесения цифровых записей в реестр цифровых транзакций. См.: О цифровых финансовых активах : законопроект № 419059-7 [Электронный ресурc]. URL: https://sozd.duma.gov.ru/bill/419059-7 (дата обращения: 20.08.2019).

19. Об использовании при совершении сделок «виртуальных валют», в частности, Биткойн [Электронный ресурc]. URL: https://www.cbr.ru/press/PR/?file=27012014_1825052.htm (дата обращения: 03.09.2019).

20. Решение № 2-160/2017 2-160/2017 M-129/2017 М-129/2017 от 26 апреля 2017 г. по делу № 2-160/2017 [Электронный pecypc]. URL: http://sudact.ru/regular/doc/qIE6zawJCy6I/ (дата обращения: 03.09.2019).

21. См.: Постановление Первомайского районного суда г. Ижевска № 1-11/2019 1-439/2018 от 30.01 .2019 по делу № 1 11/2019 [Электронный ресурc]. URL: http://sudact.ru/regular/doc/3iQdLS4G0TZQ/ (дата обращения: 20.08.2019).

22. Постановление Девятого арбитражного апелляционного суда от 15 мая 2018 г. № 09АП-16416/2018 [Электронный ресурс]. Доступ из ИПС «ГАРАНТ».

23. См., напр.: Берестень В.И. Коррупция и ее общественная опасность : учеб.-метод. пособие. Минск, 2005 ; Бородко Н.П. Коррупция и ее общественная опасность // Труды Белорусского государственного университета. Серия 5. Политология, фрилософия, история, филология. 2009. № 5. С. 61-63 ; Нуртаев Р.Т. Актуальные проблемы дальнейшего противодействия коррупции в Казахстане // Вестник Института законодательства и правовой информации Республики Казахстан. 2015. № 3 (39). С. 13-20.

\section{References:}

Bakradze, AA \& Aminov, DI 2014, 'On "Strengths" and "Weaknesses" of the Decision of the Plenum of the Supreme Court of the Russian Federation as of July 09, 2013 No. 24 on Case Law on Bribery and Other Corruption Crimes', Vestnik Akademii ekonomicheskoy bezopasnosti MVD Rossii, no. 2, pp. 45-49, (in Russian).

Beresten, VI 2005, Corruption and Its Social Danger: Study Guide, Minsk, (in Russian).

Borodko, NP 2009, 'Corruption and Its Social Danger', Trudy Belorusskogo gosudarstvennogo universiteta. Seriya 5. Politologiya, filosofiya, istoriya, filologiya, no 5, pp. 61-63, (in Russian).

Budatarov, SM 2004, 'Extortion: Criminal Legal Description' Sibirskiy yuridicheskiy vestnik, no. 2, pp. 62-68, (in Russian).

Feoktistov, MV 2000, 'Theoretical and Practical Issues of Bribery and Commercial Bribery', Sovremennye problemy bor'by s transnatsional'noy prestupnost'yu, Krasnodar, pp. 216-217, (in Russian).

Groshev, AV 2008, Liability for Bribery (Theoretical and Practical Issues), Krasnodar, p. 37, (in Russian).

Kozachenko, IYa, Neznamova, ZA \& Novoselov, GP (eds.) 1997, Criminal Law. Special Part, Moscow, p. 609, (in Russian).

Kuzmina, NV 2015, 'Legislative Mechanisms in the Field of Anti-Corruption: Development and Implementation Issues', Vestnik Kostromskogo gosudarstvennogo tekhnologicheskogo universiteta. Gosudarstvo i pravo: voprosy teorii i praktiki, no. 1, p. 132, (in Russian).

Nurtaev, RT 2015, 'Relevant Issues of Further Anti-Corruption in Kazakhstan', Vestnik Instituta zakonodatel'stva i pravovoy informatsii Respubliki Kazakhstan, no 3 (39), pp. 13-20, (in Russian).

Ozhegov, SI \& Shvedova, NYu (ed.) 1990, Russian Language Dictionary: 70,000 Words, Moscow, p. 741, (in Russian).

Prokhorova, ML \& Markov, AA 2017, 'Bribery Mediation: Some Law Making and Law Enforcement Issues', Obshchestvo: politika, ekonomika, pravo, no. 6, pp. 65-67, https://doi.org/10.24158/pep.2017.6.16.

Volzhenkin, BV 2005, Official Misconduct: Legal and Case-Law Commentary, St. Petersburg, p. 196, (in Russian). 